\title{
Methods of deconditioning persisting avoidance: Intracranial stimulation as a counterconditioner
}

\author{
BRUCE M. BECKER, DEBRA J. MAGNUSON, and LARRY D. REID \\ Bradley University, Peoria, Illinois 61606
}

\begin{abstract}
Rats were fixed with a chronically indwelling electrode for intracranial stimulation (ICS) of the lateral hypothalamus. Subsequent to verification that rats would barpress for ICS, they were trained in an automated one-way avoidance chamber to avoid footshock by climbing to a ledge. After 50 daily training trials on 3 consecutive days, the footshock was terminated. One of three treatments was then programmed: (a) response prevention (retracting the ledge, forcing the rat to stay on the previously shocking grid), (b) periodic ICS during response prevention, or (c) ICS outside the chamber without response prevention. Three days later, persisting avoidance behavior in the rat was measured. It was concluded that ICS during response prevention was most effective in reducing persisting avoidance, followed by response prevention alone, and finally ICS outside the chamber.
\end{abstract}

Testing ideas of the behavioral therapy movement was handicapped by the lack of an efficient counterconditioner of anxiety-fear to use in convenient laboratory paradigms. Both food and drugs had been used (Moltz, 1954; Nelson, 1966, 1967), but both putative counterconditioners are severely limited (Reid, 1973). Anxiety-fear suppresses eating, making it difficult to titrate the degree of food deprivation against the level of anxiety-fear to allow for counterconditioning. Not enough is known about drugs as counterconditioners of anxiety-fear to use them in a standard procedure to test other hypotheses. Because there were no efficient counterconditioners to use, the conclusion was drawn that counterconditioning was an unproven and perhaps limited procedure with respect to reconditioning anxiety-fear (Wilson \& Davison, 1971). The lack of a procedure to test counterconditioning parameters, however, was overcome by the use of the technology of intracranial stimulation (ICS) in freely moving subjects (Gordon \& Baum, 1971; Reid, 1973).

Using rats, ICS, and procedures of the automated one-way avoidance chamber of Baum $(1965,1970)$, various methods have been tested for their ability to reduce anxiety-fear-avoidance. The typical arrangement is to first establish avoidance by using footshock, then terminate the possibility of shock, and then observe the persisting avoidance. Between termination of the possibility of shock and tests for persisting avoidance, various treatments were programmed. A treatment's efficacy is assessed by comparing the endurance of persisting avoidance following that treatment to the endurance of avoidance following other treatments.

Supported by Grant DA-01049 from the National Institute of Drug Abuse, DHEW, and by a grant from Bradley University's Board for Research. We thank Harold J. Covey for his assistance.
The condition of no treatment, of course, leads to enduring persisting avoidance, and amount of perseveration of avoiding is related to training variables, including number of training trials. With the same training preceding treatments, response prevention, counterconditioning, and reinforcement procedures have been compared. Response prevention (a procedure similar to flooding or implosion) in the paradigm of Baum typically involves removing any opportunity to climb to the ledge, thereby trapping the rat on the previously shocking grid. Counterconditioning involved programming positive ICS (ICS that, when given contingently, supports leverpressing) during response prevention. Reinforcement procedures used the ICS to reinforce classes of behavior during response prevention. The outcomes of these tests demonstrated that the procedures were not equally effective, and their order of effectiveness from most to least effective were (a) reinforcement for behavior incompatible with ledge climbing, (b) counterconditioning, and (c) response prevention (Buss \& Reid, 1973; Gordon \& Baum, 1971; Hunsicker, Nelson, \& Reid, 1973; Paxton, Mejta, \& Reid, 1974; Prado-Alcala, Bush, Steele, \& Reid, 1973; Prado-Alcala \& Reid, 1974; Voss, Mejta, \& Reid, 1974).

Although it is believed that these tests clarify a number of issues, a criticism could be leveled. In experiments in which ICS was used, the persisting avoidance test immediately followed the treatment using ICS. Perhaps ICS has some relatively prolonged effects interfering with avoidance and the procedures do not test parameters of conditioning but merely capitalize on the putative aftereffects of ICS. A test of that criticism is to separate treatment and testing, since any reputed aftereffects of ICS would be of short duration, but on the other hand, it is known that conditioned responses are 
enduring. This experiment separated treatment and testing by 3 days. Outcomes again demonstrate that counterconditioning is more effective than response prevention.

In addition to testing the various training regimens for deconditioning persisting avoidance, the general procedures of Baum (1970) have been used to test a variety of drugs for their efficacy in reducing persisting avoidance. In one extended series of tests (Taub, Taylor, Smith, Kelley, Becker, \& Reid, 1977), rats were given 50 training trials a day on 3 consecutive days, given response prevention under the influence of a dose of a drug, and then tested for persisting avoidance 3 days after their treatment. In these tests, none of the popular psychotropics used to treat irrational anxiety-fear-avoidance in human clients led to a reduction in persisting avoidance. In fact, doses of chlordiazepoxide (Librium) led to greater persisting avoidance. A potential criticism of these tests is that, under the conditions of testing, no procedure would effectively reduce persisting avoidance and that therefore the drugs were submitted to an unfair test of their potential efficiency. This experiment demonstrated that a counterconditioning treatment in the same regimen of training and testing as used to test the drugs did effectively reduce persisting avoidance. Therefore, the conclusion that the drugs were ineffective was strengthened.

\section{METHOD}

\begin{abstract}
Subjects
The subjects were 34 adult male albino rats housed individually with food and water always available. Each was fixed, using standard procedures, with a chronically indwelling bipolar electrode for ICS. Electrodes (Plastic Products) were stainless steel wires insulated except at the cross section of their tips. Site of ICS, verified by direct inspection of brain, for all rats receiving ICS as part of the procedures was the lateral hypothalamic area. Rats that eventually got ICS as part of the procedures pressed rapidly for ICS during brief daily sessions. They pressed more than 40 times/min, with each press resulting in a single train of ICS.
\end{abstract}

\section{Apparatus \\ ICS was $60-\mathrm{Hz}$ sine waves of $0.30 \mathrm{sec}$. Intensity of ICS was individually selected for each rat and was always between 20 and $40 \mu \mathrm{A}$, rms. The main procedures were in an automated one-way avoidance box modeled after one described by Baum (1965) and was the same one as used by Taub et al. Briefly, it was a clear Plexiglas box $(30 \times 27.5 \times 38 \mathrm{~cm})$ fitted with an electrifiable grid and a retractable ledge $(6 \times 27.5 \mathrm{~cm}, 14 \mathrm{~cm}$ above grid floor). The Grason-Stadler shock source and scrambler was always set to deliver $1.3 \mathrm{~mA}$. Photoelectrically activated relays detected the presence of the rat on the ledge.}

\section{Procedure}

Subsequent to surgery for fixing electrodes, training to press for ICS, selection of an intensity of ICS that sustained pressing for ICS, and daily sessions with ICS, rats began avoidance training. The training and testing procedures were nearly the same as those of Taub et al. (1977).

A rat, unhabituated to the chamber, was placed on the grid of the apparatus. Ten seconds later, shock began and continued until the rat climbed onto the ledge. After $30 \mathrm{sec}$ on the ledge, the ledge moved out of the box, dropping the subject to the grid.
After its retraction, the ledge immediately returned to the box to begin a new trial. On subsequent trials, the subject were given $10 \mathrm{sec}$ to avoid shock by climbing onto the ledge; otherwise a rat was shocked until it escaped. The rat was allowed $30 \mathrm{sec}$ on the ledge with every trial.

Rats received 50 trials a session. There were three sessions, one daily for 3 consecutive days. Consequently, rats received 150 trials prior to treatments. On the 47th trial of the third session, all rats were not allowed to avoid and sustained $1 \mathrm{sec}$ of shock. This procedure was introduced to insure that all rats had taken a shock shortly before termination of training and institution of treatment.

After the 150th trial, footshock was terminated for the balance of the procedure. A subject was removed from the ledge and returned to its home cage for $30 \mathrm{~min}$. A subject was then returned to the room of the apparatus, where it received one of three treatments. One group of 13 rats got $10 \mathrm{~min}$ of response prevention without any other treatment, i.e., they were placed on the grid with the ledge retracted from the box for $10 \mathrm{~min}$. One group of 10 rats got $10 \mathrm{~min}$ of response prevention with periodic ICS. Every $1.3 \mathrm{sec}$, there was $.3 \mathrm{sec}$ of ICS. One group of 11 rats received "no treatment," i.e., they were placed in a pail next to the chamber, where they got periodic ICS.

All subjects were then tested $72 \mathrm{~h}$ after their respective treatments for the extent of persisting avoidance responding. Testing was begun by placing the subject on the ledge, which retracted $30 \mathrm{sec}$ later, beginning the same sequence of events as the previous training trials except that footshock was never presented. Testing continued until the subject remained on the grid for 5 consecutive minutes or had accumulated 335 trials.

After the first 3 min of testing, regardless of where the subject was, it was picked up, taken out of the box, handled in a standard way, and then returned to the ledge. Previously, it had been found that some rats tend to freeze on the grid after initial retraction of the ledge and remain in that position to meet deconditioning criterion. The brief handling interrupted most freezing behavior and did not interfere with responding without freezing.

\section{RESULTS}

These subjects, like other rats in this paradigm, quickly learned to avoid and avoided nearly without fail after the first trials (see Taub et al., 1977, for training scores from a large number of subjects). A Kruskal-Wallis ANOVA, corrected for ties, was performed on number of shocks taken during training, with subjects grouped according to their eventual treatments. That ANOVA yielded an $\mathrm{H}(2)=.5$, $p>.7$. These results lead to the suggestion that rats did not differ prior to treatments.

Figure 1 is a summary of the results and includes data of Taub et al. (1977). The procedures of response prevention of this experiment and Taub et al.'s study were the same. The procedures of no treatment of this paper and Taub et al.'s were the same, except the subjects of Taub et al. received no special additional treatment in the pail. The outcomes with similar procedures from the two experiments are very similar (Figure 1).

A Kruskal-Wallis ANOVA, corrected for ties, of the data of Figure 1 of this experiment, yielded an $\mathrm{H}(2)=9.59, \mathrm{p}<.01$. A Mann-Whitney $\mathrm{U}$ test comparing scores of no treatment to those of response prevention yielded a $U(11,13)=41, p<.10$; comparing scores of no treatment to those of response prevention plus ICS yielded a $\mathrm{U}(10,11)=$ 


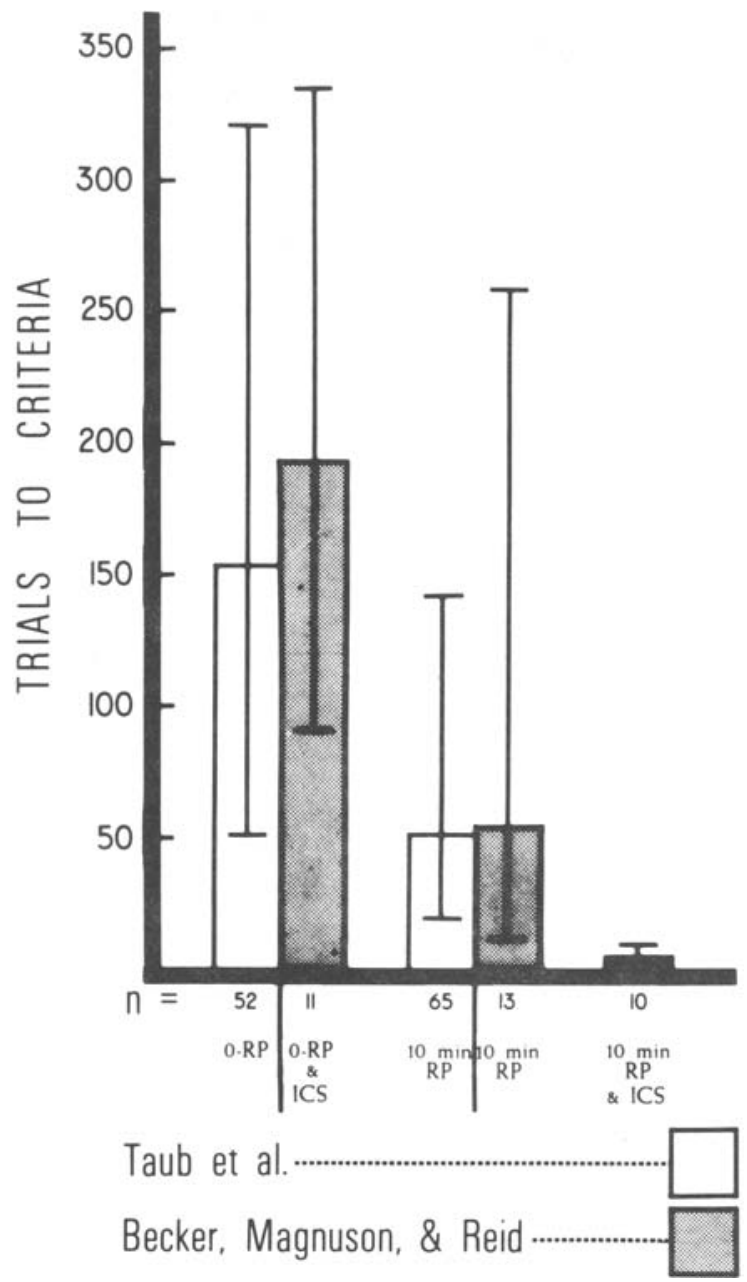

Figure 1. Bars represent median trials to criteria. The lines represent the limits of the interquartile ranges. The open bars depict performances of rats from Taub et al. (1977). The shaded bars depict performances of the three groups of this experiment. $R P=$ response prevention. 10 Min RP \& ICS = periodic intracranial stimulation during $10 \mathrm{~min}$ of response prevention.

16.5, $\mathrm{p}<.02$. A Mann-Whitney $U$ between scores of response prevention and response prevention plus ICS was $U(10,13)=26, p<.02$.

\section{DISCUSSION}

The results clearly indicate that response prevention plus ICS leads to less persisting avoidance than the procedures of response prevention or no treatment. Consequently, the effects of the ICS seen in other, similar studies is not due to carry-over effects from the immediately preceding ICS, but represents conditioning, or better yet, counterconditioning.

These results strengthen the conclusions drawn in Taub et al. (1977). Their results indicated that hardly any psychotropics tested led to less persisting avoidance than response prevention itself and, in fact, showed that some agents actually potentiated persisting avoidance. It was concluded that drugs were inefficient adjuncts to response prevention. The results of this experiment indicate that a counterconditioning procedure can be effective with the same amount of response prevention. The animal laboratory data, although limited, clearly indicate that the procedure of choice for reducing anxietyfear-avoidance is a "behavioral technique" and not a "pharmacological technique."

\section{REFERENCES}

BAUM, M. An automated apparatus for avoidance training of rats. Psychological Reports, 1965, 16, 1205-1211.

BAUM, M. Extinction of avoidance responding through response prevention (flooding). Psychological Bulletin, 1970, 74, 276-284.

Buss, R. S., \& REID, L. D. Deconditioning persisting avoidance: Spacing counterconditioning periods during response prevention. Bulletin of the Psychonomic Society, 1973, 2, 418-420.

Gordon, A., \& BAUM, M. Increased efficacy of flooding (response prevention) in rats through positive intracranial stimulation. Journal of Comparative and Physiological Psychology, 1971, 75, 68-72.

Hunsicker, J. P., Nelson, T. C., \& Reid, L. D. Two kinds of intracranial stimulation as counterconditioners of persisting avoidance in rats. Physiological Psychology. 1973, 1, 227-230.

MolTz, H. Resistance to extinction as a function of variations in stimuli associated with shock. Journal of Experimental Psychology, 1954, 47, 418-424.

Nelson, F. Effects of two counterconditioning procedures on the extinction of fear. Journal of Comparative and Physiological Psychology, 1966, 62, 208-213.

Nelson, F. Effects of chlorpromazine on fear extinction. Journal of Comparative and Physiological Psychology, 1967, 64, 496-498.

Paxton, R. A., Mejta, C. L., \& Reid, L. D. Counterconditioning with and without response prevention in deconditioning persisting avoidance. Physiological Psychology, 1974, 2, 490-492.

Prado-Alcala, R., Bush, H., Steele, D., \& Reid, L. Brief flooding and counterconditioning as treatments for persisting avoidance. Physiological Psychology, 1973, 1, 389-393.

Prado-Alcala, R., \& Reid, L. D. Reinforcement of incompatible responses and counterconditioning as methods for deconditioning persisting avoidance. Aportanciones al analysis de la conducta: Memorias del primer Congresso Mexicano, 1974. Pp. 101-118.

REID, L. D. Processes of fear reduction in systematic desensitization: An addendum to Wilson and Davison (1971). Psychological Bulletin, 1973, 79, 107-109.

Taub, J., Taylor, P., Smith, M., Kelley, K., Becker, B., \& REID, L. Methods of deconditioning persisting avoidance: Drugs as adjuncts to response prevention. Physiological Psychology, 1977, 5, 67-72.

Voss, E., Mejta, C., \& Reid, L. Methods of deconditioning persisting avoidance: Response prevention and counterconditioning after extensive training. Bulletin of the Psychonomic Society, 1974, 3, 345-347.

Wilson, E. T., \& Davison, G. C. Processes of fear reduction in systematic desensitization: Animal studies. Psychological Bulletin, 1971, 76, 1-14.

(Received and accepted for publication November 18, 1976.) 